Artikel Penelitian

\title{
KORELASI ANTARA NILAI ANKLE BRACHIAL INDEX DENGAN DERAJAT KAKI DIABETES KLASIFIKASI WAGNER DI RSUP DR M.DJAMIL PADANG
}

\author{
Rahmat Taufik ${ }^{1}$, Raflis Rustam¹, Vendry Rivaldy ${ }^{1}$, Hafni Bachtiar ${ }^{2}$
}

\begin{abstract}
Abstrak
Diabetes Mellitus merupakan penyakit yang merupakan epidemi global dan menyumbang angka kematian tertinggi di dunia. Salah satu komplikasi diabetes adalah penyakit arteri perifer (PAP), suatu kondisi yang ditandai oleh penyumbatan dalam arteri ekstremitas inferior. Tingkat keparahan PAP dapat diperiksa dengan modalitas pemeriksaan non-invasif seperti pemeriksaan $A B I$ (ante brachial index). Derajat keparahan kaki diabetes dapat di kategorikan berdasarkan klasifikasi Wagner. Penelitian ini bertujuan untuk mengetahui korelasi antara nilai $\mathrm{ABI}$ dengan derajat keparahan kaki diabetik klasifikasi Wagner pasien di RS M Djamil Padang. Dengan metode survei analitik desain cross sectional, pada pasien dengan kaki diabetik dilakukan pemeriksaan $\mathrm{ABI}$ dan pemeriksaan derajat kaki diabetik klasifikasi Wagner. Data kemudian dianalisis dengan menggunakan uji nonparametrik dengan tingkat kepercayaan 95\%. Signifikansi dari hasil tes ditentukan oleh nilai $p<0,05$. Dari total 48 sampel diperoleh bahwa nilai $\mathrm{ABI}$ adalah obstruksi ringan pada 23 orang $(47,92 \%)$, dan sebagian besar pasien kaki diabetes klasifikasi Wagner adalah derajat 1 sebanyak $17(35,42 \%)$. Uji statistik menemukan hubungan yang signifikan antara nilai $\mathrm{ABI}$ dengan derajat kaki diabetik klasifikasi Wagner $(p=0,000)$. Dapat disimpulkan, terdapat hubungan yang signifikan antara nilai ABI dengan derajat kaki diabetik klasifikasi Wagner di RSUP Dr M. Djamil Padang.
\end{abstract}

Kata Kunci: kaki diabetes, klasifikasi Wagner, ante brachial indeks

\section{ABSTRACT}

Diabetes Mellitus is a global epidemic disease and accounts for the highest mortality rate in the world. One of its complications is Peripheral Arterial Disease (PAP) which characterized by blockages in the arteries of inferior extremity. The severity of PAP can be detected and determined by a non-invasive method namely $\mathrm{ABI}$ (ante brachial index). The degree of severity of diabetic foot can be classified into several categories based on Wagner classifications. This study aimed to determine the correlation between the values of $A B I$ with the degree of Wagner classification-diabetic foot of patients in M Djamil Padang hospital. Analytical survey with cross sectional design has been done. The variables needed were measured and analysed with a non-parametric test with a 95\% confidence level to determine the relationships between variables. Of 48 samples, 23 people (47.92\%) were having mild obstruction of $A B I$ values, and about one-third of the samples $(35,42 \%)$ were having first degree of diabetic foot based on Wagner classification. Statistical analysis showed a significant correlation between $A B I$ values and the degree of diabetic foot based on Wagner classification $(p=0.000)$. To be concluded, there was a significant correlation between $A B I$ values and the degree of Wagner classification-diabetic foot in M.Djamil Padang hospital.

Keywords: diabetic foot, Wagner classification, ante brachial index

Afiliasi Penulis: 1. Bagian IImu Bedah Fakultas Kedokteran Universitas Andalas/RSUP. Dr. M. Djamil Padang, 2. Bagian IImu Kesehatan Masyarakat Universitas Andalas, Korespondensi: Rahmat Taufik, Jl. Peritnis Kemerdekaan No. 94, PO BOX 49 Padang 25127, Email: taufikrt2209@gmail.com, HP: 082170158396. 


\section{PENDAHULUAN}

Diabetes Melitus (DM) adalah penyakit yang merupakan epidemik global dan menyumbang angka kematian tertinggi karena penyakit. Diperkirakan terdapat 366 juta pasien DM di seluruh dunia pada tahun 2011. Pada tahun 2030 diperkirakan angka tersebut mencapai 552 juta pasien. ${ }^{1}$ Prevalensi tertinggi adalah di negara-negara berkembang. Dalam perjalanan penyakitnya, DM akan mempengaruhi pembuluh darah mikro dan makrosirkulasi, sehingga terjadi suatu komplikasi akut atau kronis dari DM tersebut yang berdampak pada kualitas hidup pasien. ${ }^{2}$

Dua puluh lima persen pasien DM akan mengalami ulkus kaki diabetes dalam masa hidupnya. Insiden terjadinya ulkus kaki diabetes adalah sekitar 2,0-6,8\% per tahun dari seluruh populasi pasien DM. Ulkus inilah yang memicu terjadinya infeksi dan amputasi. Lima puluh persen ulkus akan terinfeksi dan dua puluh persen membutuhkan tindakan amputasi. $^{1}$

Salah satu komplikasi dari DM adalah Penyakit Arteri Perifer (PAP), yaitu suatu kondisi yang ditandai dengan adanya sumbatan pada arteri ekstremitas inferior. Adanya PAP merupakan faktor yang berperan penting pada ulkus kaki diabetes. Pada pasien DM, PAP yang ditemukan sering kali lebih berat dengan kalsifikasi arteri yang hebat. Lesi seringnya terletak pada arteri di bawah lutut, mulai dari arteri poplitea, arteri tibialis anterior yang kemudian menjadi arteri dorsalis pedis dan arteri tibialis posterior sampai ke distal. ${ }^{1,2}$ Adanya PAP menyebabkan perfusi ke distal dari letak lesi arteri ekstremitas inferior menurun sehingga oksigenasi jaringan di daerah ulkus kaki diabetes minimal, dan mengakibatkan kerusakan jaringan yang lebih luas dan sulit untuk sembuh. ${ }^{1,2,3}$

Berbagai langkah diagnostik dan terapi dapat dikerjakan sesuai keadaan pasien. Umumnya kelainan pembuluh darah perifer dapat dikenali melalui berbagai cara sederhana seperti perubahan warna dan suhu kulit, perabaan arteri dorsalis pedis dan arteri tibialis posterior, serta pengukuran tekanan darah. Disamping itu, saat ini juga tersedia berbagai fasilitas mutakhir untuk mengevaluasi keadaan pembuluh darah, mulai dengan cara non invasif, semi invasif dan invasif. Pemeriksaan non invasif diantaranya pemeriksaan Ankle Brachial Index (ABI), Ankle pressure, Toe pressure, TcPO2 dan pemeriksaan echo doppler. Pemeriksaan semi invasif seperti digital subtraction angioraphy (DSA), magnetic resonance angiography (MRA) atau computed tomography angiography (CTA). ${ }^{3}$

Pemeriksaan $\mathrm{ABI}$ adalah modalitas pemeriksaan yang bersifat non-invasif dan dapat mendeteksi sekaligus menentukan tingkat keparahan PAP. ABI didefinisikan sebagai rasio antara tekanan darah sistolik pada kaki dengan tekanan darah sistolik pada lengan. Evaluasi PAP yang didapatkan dari $A B I$ dapat menjadi dasar diagnosis, penentuan 
terapi, dan evaluasi terapi yang diberikan. $^{3}$

Pemeriksaan $\mathrm{ABI}$ sebaiknya rutin dilakukan pada semua pasien dengan kaki diabetes guna mendeteksi adanya PAP pada pasienpasien tersebut. ${ }^{3}$ Deteksi dini kelainan arteri perifer pada kasus ulkus kaki diabetes akan mempercepat tindakan intervensi vaskular yang dibutuhkan untuk mempercepat penyembuhan ulkus sehingga diharapkan kualitas hidup pasien akan cepat membaik pula. ${ }^{2,3,4}$

Berbagai macam klasifikasi kaki diabetes, mulai dari yang sederhana seperti klasifikasi Edmons dari King's College Hospital London, klasifikasi Liverpool yang lebih ruwet, klasifikasi Texas sampai dengan klasifikasi Wagner yang lebih kompleks dan lebih terkait dengan pengelolaan kaki diabetes, dan yang terakhir yaitu klasifikasi PEDIS. ${ }^{4,5}$

Berdasarkan pemaparan teori di atas, dapat diasumsikan bahwa adanya hubungan antara nilai $A B I$ dengan derajat keparahan kaki diabetes dan klasifikasi Wagner Untuk itu penulis terdorong untuk melakukan penelitian mengenai korelasi antara nilai $\mathrm{ABI}$ dengan derajat keparahan kaki diabetes dan klasifikasi Wagner.

\section{METODE}

Desain penelitian ini adalah cross sectional study. Penelitian dilakukan di RSUP. Dr. M. Djamil Padang pada bulan Pebruari sampai dengan Mei 2015. Populasinya adalah pende- rita kaki diabetes yang masuk ke IGD, poliklinik bedah vaskuler, pasien di ruang rawat inap bedah dan pasien di ruang rawat inap endokrin bagian IImu Penyakit Dalam, khususnya pasien yang rawat bersama dengan sub bagian Bedah Vaskuler. Jumlah sampel penelitian adalah sebanyak 48 orang dengan menggunakan teknik consecutive. Pemeriksaan langsung dilakukan pada pasien kaki diabetes. Pada kaki diabetes, dilakukan pemeriksaan tekanan darah arteri pada ankle (arteri dorsalis pedis dan arteri tibialis posterior, dimana dipilih tekanan sistole tertinggi diantara kedua arteri tersebut), dan tekanan darah arteri pada lengan (arteri brachialis). Kemudian dicari rasio antara tekanan darah pada ankle dengan tekanan darah di lengan (ABI). Nilai ABI yang didapatkan apakah bernilai normal, obstruksi ringan, obstruksi sedang, obstruksi berat. Kemudian pada kaki yang sama juga diperiksa klasifikasikasi berdasarkan Wagner. Dimana ada enam tingkatan, yaitu mulai derajat 0 sampai dengan derajat 5. Jika pada satu pasien terdapat kondisi kaki yang berbeda derajatnya, maka yang dipakai sebagai sampel penelitian adalah kondisi kaki dengan derajat yang lebih parah. Pada penelitian ini untuk kaki derajat lima, tidak bisa diperiksa karena kondisi kaki menyebabkan pemasangan probe doppler maupun manset tensimeter tidak dapat dilakukan, sehingga kaki derajat lima menjadi kriteria eksklusi. Data diolah dengan komputer dan dianalisis menggunakan uji non-parametrik yaitu 
uji kruskal-wallis dengan derajat kepercayaan $95 \%$.

\section{HASIL DAN PEMBAHASAN}

Hasil yang didapatkan pada penelitian ini mengenai distribusi frekuensi penderita DM berdasarkan umur, jenis kelamin, kaki yang diperiksa, lama menderita DM, riwayat keluarga, nilai $\mathrm{ABI}$, dan klasifikasi Wagner dapat dilihat pada tabel 1. Kejadian DM lebih banyak ditemukan pada umur 40-60 tahun yaitu sebesar $36(75 \%)$ kasus, sedangkan kasus yang paling sedikit pada usia 71-80 tahun sebanyak $3(6,25 \%)$ kasus. Jenis kelamin penderita hampir sama antara laki-laki dan perempuan yaitu laki-laki $23(47,91 \%)$ dan perempuan 25 (52,09\%). Komplikasi PAP lebih banyak ditemukan pada kaki kanan penderita yaitu 33 (68,75\%).Penelitian ini juga menemukan lamanya menderita DM paling banyak pada rentang waktu 6-10 tahun yaitu 20 (41,67\%) kasus dan sekitar 24 (50\%) kasus mempunyai riwayat keluarga menderita DM.

Nilai $\mathrm{ABI}$ yang didapatkan menunjukkan kejadian obstruksi ringan lebih banyak ditemukan yaitu sebesar $23(47,92 \%)$ kasus. Hasil penelitian menurut klasifikasi Wagner didapatkan bahwa derajat 1 paling banyak ditemukan yaitu 17 (35,42\%) kasus. Hubungan umur dengan nilai $A B I$ secara statitik tidak bermakna $(p=0,454)$ dapat dilihat pada tabel 2 . Hubungan yang bermakna secara statistik didapatkan antara nilai $A B I$ dengan lamanya menderita DM dan klasifikasi Wagner, nilai $p<0,005$.
Tabel 1. Distribusi Frekuensi Penderita Kaki Diabetes Berdasarkan Umur, Jenis Kelamin, Kaki yang Diperiksa, Lama DM, Riwayat Keluarga, Nilai ABI dan Klasifikasi Wagwner

\begin{tabular}{cc}
\hline Distribusi DM & Frekuensi (\%) \\
\hline Umur (Tahun) & $18(37,50)$ \\
$40-50$ & $18(37,50)$ \\
$51-60$ & $9(18,75)$ \\
$61-70$ & $3(6,25)$ \\
$71-80$ & \\
Jenis Kelamin & $23(47,91)$ \\
Laki-laki & $25(52,09)$ \\
Perempuan & \\
Lokasi & $33(68,75)$ \\
Kaki Kanan & $15(31,25)$ \\
Kaki Kiri & \\
Lama DM (Tahun) & $19(39,58)$ \\
$1-5$ & $20(41,67)$ \\
$6-10$ & $9(18,75)$ \\
$11-15$ &
\end{tabular}

Riwayat Keluarga

Ada

$24(50 \%)$

Tidak Ada $24(50 \%)$

Nilai $A B I$

Normal

$13(27,08)$

Obstruksi ringan

$23(47,92)$

Obstruksi sedang

$10(20,83)$

Obstruksi berat

$2(4,17)$

Klasifikasi Wagner

Derajad 0

Derajat 1

$17(35,42)$

Derajat 2

$11(22,91)$

Derajat 3

$10(20,83)$

Derajat 4 
Tabel 2. Hubungan Umur dengan Nilai ABI

\begin{tabular}{cccccc}
\hline UMUR & \multicolumn{5}{c}{ Nilai ABI } \\
\cline { 2 - 5 } (Tahun) & $\begin{array}{c}\text { Normal } \\
\mathbf{n}(\%)\end{array}$ & $\begin{array}{c}\text { Obstruksi } \\
\text { Ringan } \\
\mathbf{n}(\%)\end{array}$ & $\begin{array}{c}\text { Obstruksi Sedang } \\
\mathbf{n}(\%)\end{array}$ & $\begin{array}{c}\text { Obstruksi } \\
\text { Berat } \\
\mathbf{n}(\%)\end{array}$ & $\mathbf{p}$ \\
\hline $40-50$ & $6(33,3)$ & $10(55,6)$ & $2(11,1)$ & $0(0)$ & \\
$51-60$ & $5(29,4)$ & $6(35,3)$ & $5(29,4)$ & $1(5,9)$ & 0,454 \\
$61-70$ & $2(20,0)$ & $5(50,0)$ & $2(20,0)$ & $1(10,0)$ & \\
$71-80$ & $0(0)$ & $2(66,7)$ & $1(33,3)$ & $0(0)$ & \\
\hline
\end{tabular}

Tabel 3. Hubungan Lama Menderita DM dengan Nilai ABI

\begin{tabular}{|c|c|c|c|c|c|}
\hline \multirow{2}{*}{$\begin{array}{c}\text { LAMA } \\
\text { DM } \\
\text { (Tahun) }\end{array}$} & \multicolumn{4}{|c|}{ Nilai ABI } & \multirow[b]{2}{*}{$\mathbf{p}$} \\
\hline & $\begin{array}{c}\text { Normal } \\
\text { n (\%) }\end{array}$ & $\begin{array}{c}\text { Obstruksi } \\
\text { Ringan } \\
\text { n (\%) }\end{array}$ & $\begin{array}{c}\text { Obstruksi Sedang } \\
\text { n (\%) }\end{array}$ & $\begin{array}{c}\text { Obstruksi } \\
\text { Berat } \\
\text { n (\%) }\end{array}$ & \\
\hline $1-5$ & $9(50,0)$ & $9(50,0)$ & $0(0)$ & $0(0)$ & \\
\hline $6-10$ & $4(19,0)$ & $11(52,4)$ & $6(28,6)$ & $0(0)$ & 0,000 \\
\hline $11-15$ & $0(0)$ & $3(33,3)$ & $4(44,4)$ & $2(22,2)$ & \\
\hline
\end{tabular}

Tabel 4. Hubungan Klasifikasi Wagner dengan Nilai ABI

\begin{tabular}{|c|c|c|c|c|c|}
\hline \multirow{2}{*}{$\begin{array}{l}\text { Klasifikasi } \\
\text { Wagner }\end{array}$} & \multicolumn{4}{|c|}{ Nilai ABI } & \multirow[b]{2}{*}{$\mathbf{p}$} \\
\hline & $\begin{array}{c}\text { Normal } \\
\text { n (\%) }\end{array}$ & $\begin{array}{c}\text { Obstruksi } \\
\text { Ringan } \\
\text { n (\%) }\end{array}$ & $\begin{array}{c}\text { Obstruksi } \\
\text { Sedang } \\
\text { n (\%) }\end{array}$ & $\begin{array}{c}\text { Obstruksi } \\
\text { Berat } \\
\text { n (\%) }\end{array}$ & \\
\hline 0 & $5(83,3)$ & $1(16,7)$ & $0(0)$ & $0(0)$ & \\
\hline 1 & $8(47,1)$ & $8(47,1)$ & $0(0)$ & $0(0)$ & 0,000 \\
\hline 2 & $0(0)$ & $9(81,8)$ & $2(18,2)$ & $0(0)$ & \\
\hline 3 & $0(0)$ & $4(36,4)$ & $7(63,6)$ & $0(0)$ & \\
\hline 4 & $0(0)$ & $0(0)$ & $1(33,3)$ & $2(66,7)$ & \\
\hline
\end{tabular}

Kaki diabetes merupakan salah satu komplikasi dari diabetes mellitus yang paling ditakuti, karena dapat menyebabkan cacat bahkan kematian. 9-17 Nasib pasien diabetes melitus dengan persoalan kaki sampai saat ini masih sangat mengecewakan. ${ }^{5-7}$ Beberapa konsep dasar yang masih kurang tepat dalam pengelolaannya, sehingga mengakibatkan lebih banyak pasien yang terpaksa kakinya harus diamputasi, padahal sebenarnya kaki 
tersebut dapat diselamatkan jika ditangani dengan lebih dini, lebih tepat dan lebih baik. Petanda awal iskemi perifer segera dicari dan diperhatikan untuk mencegah terjadi kaki diabetes. ${ }^{17-27}$

Penelitian ini didapatkan rerata umur umumnya hampir sama dengan peneliti lain oleh Supriyanto dkk yaitu usia 56,5 tahun. Beberapa peneliti menemukan usia rata-rata 52,2 tahun, dan 59,3 tahun. ${ }^{28}$ Berdasarkan jenis kelamin Osei dkk di Amerika mendapat penderita DM dengan perbandingan antara laki-laki: perempuan adalah 1,7:1 dimana lakilaki lebih banyak, sedangkan Vendry $R$ menemukan perbandingan 0,55:1, yang artinya jenis kelamin perempuan lebih banyak. ${ }^{7}$ Sehingga perbedaan jenis kelamin pada beberapa peneliti tidak sama.

Hasil uji statistik dengan derajat kepercayaan 95\% menunjukkan bahwa tidak terdapat korelasi atau hubungan yang bermakna antara umur penderita kaki diabetes dengan nilai $A B I$, dengan nilai $p=0,454(p>0,05)$. Berati secara statistik bertambahnya umur tidak berhubungan terhadap bertambah beratnya nilai $A B I$ yang akan terjadi pada penderia DM.

Berdasarkan lokasi komplikasi kaki diabetes, didapatkan terbanyak di kaki kanan 28 orang, lalu kaki kiri 13 orang dan beberapa diantara pasien terdapat di kedua kaki yaitu 7 orang. Tapi berdasarkan definisi operasional sebelumnya, tetap kaki dengan tingkat keparahan yang lebih berat yang diperiksa. Maka pada kaki yang kedua kakinya ditemukan kaki diabetes, ditemukan pembagian sebagai berikut, kaki kanan 5 orang dan kaki kiri 2 orang. Peneliti lain, Supriyanto pernah menemukan hasil yang perbandingannya hampir sama, yaitu kaki kanan 19 orang, kaki kiri 10 orang dan adanya di kedua kaki 10 orang. $^{7}$

Pada pasien yang pada kedua kakinya terdapat kondisi kaki diabetes, semuanya tidak sama kondisinya, selalu ada yang lebih parah pada salah satunya. Begitu juga kalau sudah ada ulkus, kejadian ulkus juga tidak simetri. Untuk kaki diabetes derajat lima dieksklusi pada penelitian ini, oleh karena kesulitan dalam pemeriksaan $A B I$ berupa tidak bisanya dipasang probe doppler maupun manset tensimeter

Penelitian ini rerata lamanya DM adalah 6,9 tahun dengan rentang minimal 1 tahun dan maksimal 15 tahun. Pada peneliti lain ditemukan angka yang tidak jauh begitu berbeda, yaitu Supriyanto dkk rerata lama DM 8,0 tahun, dengan rentang minimal 3 tahun dan maksimal 23 tahun. Gatot $S$ dkk rerata lama DM 5,6 tahun, Lawrence dkk rerata lama DM 13,6 tahun, Yoshimasa dkk rerata lama DM pada yang non ulkus 12,8 tahun, sedang yang ulkus rerata 12,3 tahun. ${ }^{28}$ Sehingga rerata lama menderita DM pada kaki diabetes hampir sama yaitu umumnya antara range 5 sampai 15 tahun. Penelitian ini mendapatkan bahwa terdapatnya hubungan antara lama menderita DM pada kejadian kaki diabetes dengan nilai ABI. Ini berarti, bahwa bertambah lama menderita DM akan bertambah berat nilai $\mathrm{ABI}$. Penelitia ini juga didapatkan bahwa semakin berat PAP semakin berat berat derajat kaki diabetes yang ter- 
jadi. Dengan demikian didapat bahwa derajat PAP dapat mempengaruhi terjadi kaki diabetes sejalan dengan beratnya ulkus.

\section{SIMPULAN}

Penelitian ini dapat diambil kesimpulan bahwa tidak terdapat hubungan yang bermakna antara umur dengan nilai $A B I$, namun terdapat hubungan yang bermakna antara lama menderita $D M$ dengan nilai $A B I$, sehingga bertambah lama menderita

\section{DAFTAR RUJUKAN}

1. Simerjit S, Dinker RP, Chew Y. Diabetic foot ulcer-diagnosis and management. Clin Res Foot Ankle 2013;1:120.

2. Rutherford. Vascular Surgery's Premier Textbook. 6th ed. 2014; 120 46.

3. Ivy C, Elkin VL, Thomas RE. Management and prevention of diabetic foot ulcers and infections. Pharmacoeconomics 2008;26(12) :1019-35.

4. Jusi J. Dasar-dasar ilmu bedah vaskuler. Ed 4. Jakarta. Balai Penerbit Fakultas Kedokteran Universitas Indonesia; 2008.

5. Cynthia LB, David JM. Reducing the incidence of foot ulceration and ampution in diabetes. Curr Diab Rep 2004;4:413-18.

6. Vendry R. Penilaian USG aliran darah pada arteri dorsalis pedis, tibialis posterior, poplitea dan femoralis superficialis pada tungkai pasien dengan ulkus diabetes dibandingkan dengan tungkai tanpa ulkus. Divisi Bedah Vaskular, Endovaskular 2014:6-9.
DM akan bertambah berat nilai $\mathrm{ABI}$. Penelitian ini juga mendapatkan hubungan antara derajat kaki diabetes kalsifikasi Wagner dengan nilai $A B I$, sehingga semakin berat komplikasi penyakit arteri perifer semakin berat derajat kaki diabetes.

7. Eva D, Jazil K, Asman M, Syafril S. Profil ulkus diabetik pada penderita rawat inap di bagian penyakit dalam RSUP Dr. M. Djamil Padang. MKI 2008;58(1):3-7.

8. John AD. Outpatient assessment and management of the diabetic foot. Med Clin N Am 2014;98:353-73.

9. Lepantalo M. Diabetic Foot. Eur J Vas Endovas Surg. 2011;42(52): S60-S74.

10. Rebolledo FA, Soto JMT, Jorge EP. The pathogenesis of the diabetic foot ulcer: prevention and management. Global Perspe Diab Foot Ulcer 2011:155-82.

11. Edmonds ME, Foster AVM. Managing the diabetic foot. $2^{\text {nd }}$ ed. Blackwell Publishing 2006; 1-152

12. Frykberg RG, Zgonis T, Armstrong DG, Driver VR, Giurini JM, et al. A clinical practice guideline. In; diabetic foot disorders. J Foot and Ankle Surg 2006;1-66.

13. Wu S, Armstrong DG, Lavery LA, Harkless LB. Clinical examination of the diabetic foot and the identification or the at-risk patien. In: the diabetic foot. Veves A, Giurini JM, LoGerfo 
FW editors. Humana Press New Jersey 2006.

14. Kirsner RS. The standard of care for evaluation and treatment of diabetic foot ulcers.

15. Paul C, Michael E, Joanne M, David A. Best Practice Guidelines: Wound Management In Diabetic Foot Ulcers 2013:1-23.

16. Boulton AJM, Kirsner RS, Vieikyte L. Neuropathic Diabetic Foot Ulcers. New Eng J Med 2004;351: 48-55.

17. Kimberlee BH, Dane KW. Diabetic Foot Infections: Current Concept Review. Diab Foot Ankle 2012;3.

18. Katsilambros N, Dounis E, Tsapogas $\mathrm{P}$, Tentolouris $\mathrm{N}$. Atlas of the diabetic foot. John Wiley sons editors. England 2003;1-22.

19. Kleopatra A, John D. Management Diab Foot Ulcers. Diab Ther. 2012; 3(4):1-15.

20. Blanes JJ. Consensus document on treatment of infection in diabetic foot. Rev Esp Quimioter 2011;24 (4):23362.

21. Sharad PP. Understanding diabetic foot. Int J Diab Dev Ctires 2010;30(2):75-79.

22. American Diabetes Association (ADA.
Standard of medical care in diabetes. Diab Care 2012;35:S11-63.

23. Singh D. Diabetik Foot: It's Time to Shere The Burden. Calicut Med J 2006;4.

24. Edwards JS. Debridement of diabetic foot ulcers. Cochrane Datavase Systc Rev 2012;(1).

25. Martin EL. An overview of the diabetic foot: pathogenesis, management and prevention of lesions. Int J Diab Dev Countries 1994;14:39-47.

26. Cynthia F, Ifred G, Nachiappan C. The importance of diabetes foot care education in a primary care setting. $\mathrm{J}$ Diab Nursing 2012;16 (10):410-14.

27. Fard AS, Esmaelzadeh M, Larijani B. Assessment and treatment of diabetic foot ulcer. Int $\mathrm{J}$ Clin Pract 2007;61(11):1931-38.

28. Supriyanto. Hubungan antara derajat kaki diabetik dengan neuropati perifer pada penderita diabetes melitus tipe 2. Universitas Diponegoro 2001;2737. 